UNIVERSITY OF GOTHENBURG

SCHOOL OF BUSINESS, ECONOMICS AND LAW

WORKING PAPERS IN ECONOMICS

No 581

The intermediary role of microloan officers: Evidence from Ethiopia

Oleg Shchetinin and Conny Wollbrant

December 2013

ISSN 1403-2473 (print)

ISSN 1403-2465 (online)

Department of Economics

School of Business, Economics and Law at University of Gothenburg

Vasagatan 1, PO Box 640, SE 40530 Göteborg, Sweden

+46317860000, +46317861326(fax)

www.handels.gu.se info@handels.gu.se 


\title{
The intermediary role of microloan officers: Evidence from Ethiopia*
}

\author{
Oleg Shchetinin ${ }^{\dagger} \quad$ Conny Wollbrant ${ }^{\ddagger}$
}

December 12, 2003

\begin{abstract}
Microfinance institutions are key financial intermediaries between donors and borrowers in developing countries. Loan officers are crucial for establishing and maintaining the relationship between borrowers and microfinance institutions. This paper studies the impact of loan officers on the loan portfolio. We use a survey and choice experiment of 800 loan officers to estimate loan officers' preferences over loan allocation. We investigate how these preferences are affected by the organizational structure of the microfinance institution, for example, incentive provision. We pay special attention to monitoring of borrowers and loan officer discretion. The most important determinants of loan allocation are related to the financial viability of microfinance institutions rather than the pro-social mission of microfinance. We derive recommendations for the governance of microfinance institutions.
\end{abstract}

Keywords: Financial intermediation, Microfinance, Loan officers, Loan allocation, Choice experiment

\section{JEL Classification Codes: G21, L31, O16}

${ }^{*}$ We are grateful for helpful suggestions and comments from Yonas Alem. Financial support from the Adlerbertska Foundation (Adlerbertska Forskningsstiftelsen) is gratefully acknowledged. We are grateful for organizational support provided by the Association of Ethiopian Microfinance Institutions (AEMFI) and especially to Dr. Wolday Amha, and to the managers of all participating MFIs. We are grateful to the Addis Ababa University and especially to Tekie Alemu for valuable comments and his support during the entire field stage. Excellent research assistance was provided by Hailu Elias, Atnafu G. Meskel, Atlaw Alemu, Getachew Adane, Sisay Addis, Kassahum Alem, Takele Berhanu, Gelana Deme, Solomon Hmarian, Amanuel Jessehaye and Hibiret Tsehay. We are also grateful to Hailu Elias for manu insightful discussions. Remaining errors are our own.

†The University of Gothenburg, School of Business, Economics and Law, Department of Economics. Phone: +46 31 7861344. E-mail: oleg.shchetinin@economics.gu.se

¥The University of Gothenburg, School of Business, Economics and Law, Department of Economics. Phone: +46 31 7862615. E-mail: conny.wollbrant@economics.gu.se 


\section{Introduction}

Microfinance institutions (MFIs) are the main channel for providing access to finance by acting as financial intermediaries between donors and the poor in the developing world. Because of lack of collateral, the poor cannot obtain financing for their entrepreneurial projects from conventional banks and are locked in poverty traps. ${ }^{1}$ This paper contributes to the currently developing literature on the organizational structure of MFIs and its impact on financial intermediation. We focus on Loan Officers (LOs), who themselves play an intermediary role between borrowers and the MFI. In particular, we study how organizational features of MFIs, such as incentives provided to the LO, affect loan allocation and therefore shape the portfolio of clients. The LO is a key actor within the MFI and determines the success of microfinance, both in terms of social missions and financial performance.

Our paper is, to the best of our knowledge, the first to provide a detailed examination of the impact of monitoring difficulty and applicants' savings on loan allocation and the role of LO discretion in the monitoring process. Information about a borrower is acquired during monitoring and its transmission to the MFI is subject to LO discretion. Monitoring and LO discretion are particularly important in the context of microfinance due to the softness of information; borrower-MFI contracts therefore contain a substantial relational component. From the broader perspective of financial intermediation, there exists no direct channel by which borrowers can be provided direct access to funds available from donors; instead MFIs act as intermediaries. From the organizational perspective of MFIs, LOs stand out as particularly important for the delivery of financial access to the desired clientele.

In this paper, loan officers are placed at the center. The interaction of LOs with MFI clientele goes mainly through two channels: first, when evaluating applications for microloans and, second, when monitoring the performance of

\footnotetext{
${ }^{1}$ Armendáriz and Morduch (2010) provide a detailed account of the development of microfinance.
} 


\section{Donors}

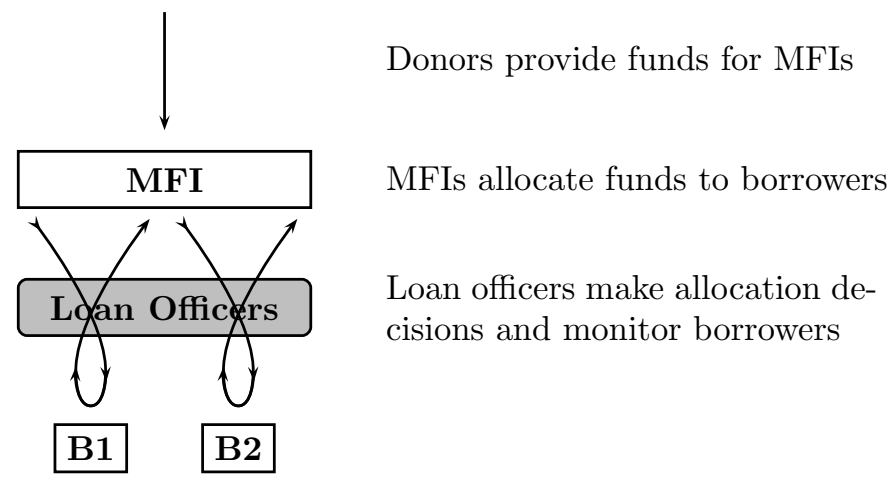

Figure 1: The flow of funds to and inside microfinance sector

the approved loan. We study in detail LOs' preferences over loan allocation, and a number of aspects related to monitoring: what makes monitoring difficult, how often do LOs exercise discretion, to what extent do they bend rules in case of unsatisfactory performance, and how proficient they are. On top of this, we study how LOs' alignment with the perceived objectives of MFIs influences their performance. Surprisingly, the literature on microfinance until very recently paid little attention to LOs and their role in microfinance (see Cole and Duflo (2004), Labie et al. (2010) and Sagamba et al. (2013) for exceptions).

Our study is based on a survey of LOs and managers of MFI branches. We managed to involve 800 LOs from 8 MFIs in Ethiopia. Our sample of LOs is representative of the whole country as it involves LOs from both big and small MFIs located in different parts of the country. An important part of the study is a choice experiment with LOs. In the choice experiment, participants were presented with a pair of applicant profiles, and were asked to indicate which one they preferred for loan allocation. Every LO was presented with 16 such pairs. Profiles contained both information about the applicant and the project. Applicant characteristics are gender, age and poverty level. These characteristics are not only relevant from a social perspective, but are often stated explicitly in MFI mission statements. Project characteristics are the probability of timely reimbursement as an indicator of project quality, difficulty 
of monitoring, loan size, and savings beyond the required minimum. In addition, LOs were presented with a questionnaire that asked about incentive practices, perceived mission of their MFI, training in MFI related activities, exercise of discretion, distribution of work tasks and a few attitudinal questions.

The choice experimental methodology employed in our study is novel in research on the internal structure of microfinance institutions. In our view, there are strong grounds for employing choice experiments for the study of this topic. Indeed, choice experiments (among other experimental methods) provide a possibility to assess factors influencing decisions of LOs and/or other involved parties, which otherwise are difficult to assess, since the necessary data is missing or very hard to collect. Controlled experiments allow observing the choices and other behaviors of economic actors and provide the necessary data. In this way, the choice experiment methodology represents an important tool which can potentially deliver new insights. ${ }^{2}$ The downside of choice experiments is that the choices made by participants are would-be choices rather than real life choices. Real choices are, however, impossible to observe since MFIs do not systematically store information about rejected applications for microloans. For this reason, empirical studies based on approved applicants will be subject to selection bias. In such circumstances, a choice experiment is a plausible alternative for studying the decisions of LOs and factors influencing these decisions.

In line with previous studies (e.g., Sagamba et al. (2013)), we find that, in general, project characteristics have stronger effects on LOs' preferences for loan allocation than social characteristics of applicants. With respect to applicant characteristics, women have a higher chance of being allocated a microloan, as do the extremely poor and those with savings beyond the required minimum. Increasing age initially benefits the applicant, but these benefits peak and later fall to become negative; the effect of age on LO preferences is therefore nonmonotonic. With respect to project characteristics, the probability of timely reimbursement has a strong positive effect on LO preferences, while the difficulty

\footnotetext{
${ }^{2}$ See Harrison and List (2004) and Levitt and List (2009) for survey of experimental economics.
} 
of monitoring has a strong negative effect.

Comparing the effect of monitoring difficulty on LO preferences by incentive type provided by the MFI, mission perception, and discretion exercised in reporting and sanctioning, we find large variation in the effect of high levels of monitoring difficulty. For instance, the effect of monitoring difficulty is less important to the LO if she is incentivized to provide loans to the poorest, and similarly, if she perceives the mission of her MFI as supporting the poor. In addition, levels of monitoring difficulty can be less important in general if the LO exercises high levels of discretion in reporting clients and recommending sanctions when guidelines state these ought to be implemented. Our results provide evidence for an important role of interactions between LO preferences and organizational features of the MFI in determining the microloan portfolio, and hence the social impact and performance of microfinance.

From a broader perspective, the organizational structure of MFIs, and its impact on decisions of LOs and on the performance of MFIs, have so far not been thoroughly investigated, except for a few studies that focus on individual MFIs. These studies find that LOs exercise significant discretion in abiding by rules set forth by the MFI in line with their own interpretation of the consequences of compliance (Canales (2011)), and that LOs often have to be prepared to negotiate, and sometimes engage in conflict with non-compliant borrowers (Battilana and Dorado (2010)). The role of the LO, therefore, is not limited to mechanical implementation of formal guidelines, but there is significant scope for LO preferences and incentives to have an important impact on the performance of the MFI.

The literature exploring the relationship between LO preferences and organizational features such as incentives and monitoring is rather nascent. Labie et al. (2010) show that incentives provided to the LO may reduce problems of discrimination in loan allocation. Agier and Szafarz (2012) show that, despite incentives being provided, LO preferences still interfere with loan allocation. Canales (2011) demonstrates that LOs tend to bend formal rules and thus ex- 
ercise substantial discretion in their operations.

Monitoring of borrowers is the crucial determinant of performance of MFI. Modern microfinance started in the 1970s and employed mainly group lending (see ch.4 in Armendáriz and Morduch (2010)), where the group peer monitoring and peer social pressure played a crucial role in alleviating the problems related to the softness of information. Currently, individual loans have become more common in microfinance (see, e.g., Cull et al. (2009)), and peer monitoring needs to be substituted by another mechanism, suitable for individual loans, to ensure good performance of the loans, for instance, proper usage and timely repayment. The alternative mechanism is to have the LO monitor borrowers, and no other alternative has yet been devised. Loan officers therefore play an important role in enforcing microloan performance and repayment by constantly monitoring borrowers.

LO discretion, i.e., "real authority", over loan allocation and sanctioning, as opposed to formal authority (see Aghion and Tirole (1997)), is an important determinant of the performance of MFIs. Microfinance can be seen as a limiting case of financing small businesses, which is known to be very sensitive to the discretion exercised by loan officers (see Hertzberg et al. (2010) and Berger et al. (2005)). Indeed, financing small businesses requires collecting and acting on soft information; relational contracting emerges as an important contract enforcement tool. The nature of relational contracting gives rise to a greater role of LO discretion. These aspects are present and amplified in the context of microfinance.

The rest of this paper proceeds as follows. Section 2 provides background information about Ethiopia and Ethiopian Microfinance. Section 3 explains our methodology. Section 4 presents results related to the monitoring process and LO discretion. Section 5 presents results on LO decisions on loan allocation. Section 6 discusses implications. Finally, section 7 concludes the paper. 


\section{The Case of Ethiopia}

\subsection{Economic background of Ethiopia}

Ethiopia is one of the poorest countries in the world with GNI per capita (PPP) of 1030 USD. ${ }^{3}$ This figure can be compared with some reference numbers: the average values for low income countries is 1303, for least developed countries it is 1498, and for Sub-Saharan Africa it is 2130. The last number is almost twice as large as the Ethiopian GNI per capita. Ethiopia is the second most populated country in Africa with a population of about 83 million people.

The economy of Ethiopia is dominated by agriculture which accounts for $47.7 \%$ of GDP. A lot of economic activity, especially of individual entrepreneurs, e.g., smallholder farmers, is geographically disperse. Additionally, the terrain is difficult and the population is scattered across many parts of the country. The combination of a very poor population with disperse economic activity amplifies the very high demand for small scale financial services.

These financial services cannot be provided by standard financial institutions and as a result, an institutional void emerges. This problem is common for developing countries, for instance, in Sub-Saharan Africa, but it is especially pressing in Ethiopia. Indeed, access to finance is the major problem for doing business in Ethiopia for all big and small enterprises (The World Bank (2011)). About one third $(33.2 \%)$ of all enterprises characterize access to finance as the main obstacle for doing business, as compared to only $20.5 \%$ for the whole subSaharan Africa. ${ }^{4} 38.4 \%$ of small firms in Ethiopia (1 - 19 employees) identify access to finance as the main problem, while for medium and large size firms these figures correspond to $29.5 \%$ and $23.8 \%$, respectively. This implies that microfinance in Ethiopia is a more important development factor than in comparable countries in Sub-Saharan Africa and that the scope for microfinance activities is perhaps larger in Ethiopia than in any other African country.

The economic environment in which Ethiopian MFIs operate is generally

\footnotetext{
${ }^{3}$ All the macroeconomic indicators in this part of the paper are taken from WDI 2010.

${ }^{4}$ The main problem for the region of Sub-Saharan Africa is access to electricity.
} 
similar to that of many other African countries. Furthermore, problems related to providing access to finance are similar all over Africa, although amplified in the Ethiopian case. In this way, the Ethiopian case is worthy of study in its own right, but is also informative for understanding microfinance in other African countries.

\subsection{An overview of microfinance in Ethiopia}

Informal financial institutions are widespread in Ethiopia and has a long history. The most common and organized are iddir and $i q u b$. Iddir is an indigenous institution where members make regular contributions to a common pool. The money from the pool can be used to support a needy member of iddir. ${ }^{5}$ In this way, iddir is an informal insurance institution. Iqub is a rotating savings and credit association. The membership in both is usually based on earlier established social ties.

The origins of formal microcredit in Ethiopia can be traced back to 1980s when some NGOs, both international and local, started microcredit programs as part of their relief and rehabilitation programs. At the time these were mainly small programs, their activity was neither coordinated nor regulated, and entry was free.

Free entry has advantages and disadvantages from the point of view of the viability of microfinance. Whereas advantages are obvious, disadvantages are more subtle. For instance, some less constrained microcredit programs may fail to implement financial discipline for the borrowers and as a result, the development impact is undermined; some borrowers fail to develop their enterprises and in fact perceive the loan as a gift.

Under uncontrolled entry, many microcredit programs funds are based on donations and lack long-term objectives. In this case, financial viability is not a concern for the program; the main objective of such an MFI is rather to disburse money to needy people. As a result, these microcredit programs do

\footnotetext{
${ }^{5}$ In iddir, money are often used to cover funeral expenses of member household.
} 
not control how the money is used by the recipients and often do not enforce repayment. Compared to MFIs that carefully select borrowers, monitor the use of loans and enforce repayment, the microcredit programs primarily aimed at disbursing money have lower operational cost and, consequently, lower interest rates. They are also typically short-lived. At the same time, their presence is likely to spoil the activity of MFIs relying on self-sustainability. The latter typically have long-term development plans and are deeply integrated in the society. This speaks in favor of controlling the entry of MFIs.

Since 1996, the activities of MFIs are regulated by a number of Proclamations. The proclamation 40/1996 requires legal registration of MFI with the National Bank of Ethiopia (NBE). It also establishes the requirement for all MFIs to be non-profit. This distinguishes microfinance in Ethiopia from most of other countries where both profit-seeking and non-profit MFIs can operate. The proclamation also requires that all MFIs should take deposits. This requirement is supposed to improve sustainability of the MFIs.

Most of the currently existing MFIs have evolved from NGOs credit programs or from Government programs, and many of them still keep strong relationships with the institutions of their origin. In 2011, there were about 30 registered MFIs.

\section{Methodology and Data}

\subsection{The Survey Design}

Our study consists of a survey and a choice experiment with LOs. In the survey we collected background information on microloan officers (age, gender, experience etc.); information on incentives provided to LOs; in-depth information on processing of applications for microloans and on the monitoring routines. We also elicited the alignment of LO views with the perceived objectives of the LO's MFI.

In the choice experiment, LOs were asked to compare 16 pairs of hypothet- 
ical applicants for a microloan. The profiles of applicants were presented in a standardized form. Each profile consisted of 7 characteristics of applicant and his/her entrepreneurial project; see Table 3.1 for the details. ${ }^{6}$ For every pair, LOs were asked to indicate which applicant is preferred for microloan attribution and how sure they are of their choice. The purpose of the choice experiment is to elicit LOs preferences over microloan allocation.

Table 1: The list of attributes and its values.

\begin{tabular}{|l|c|l|}
\hline Attribute & \# of values & List of values \\
\hline \hline Age & 5 & $18 ; 22 ; 27 ; 34 ; 44$ years \\
\hline Gender & 2 & Female; Male \\
\hline Poverty level & 3 & Poor; Very poor; Extremely poor \\
\hline $\begin{array}{l}\text { Prob. of timely } \\
\text { repayment }\end{array}$ & 4 & $\begin{array}{l}\text { Graphical scale, ranging from "half of the } \\
\text { cases" to almost sure }\end{array}$ \\
\hline $\begin{array}{l}\text { The size of the } \\
\text { loan }\end{array}$ & 3 & Small; Medium; Large \\
\hline $\begin{array}{l}\text { Difficulty of } \\
\text { monitoring }\end{array}$ & 3 & Easy; With some difficulties; Difficult \\
\hline $\begin{array}{l}\text { Monthly sav- } \\
\text { ings }\end{array}$ & 3 & $\begin{array}{l}\text { At the minimal required level; Slightly } \\
\text { more; Much more }\end{array}$ \\
\hline
\end{tabular}

The survey of LOs and the choice experiment were merged into one questionnaire. This questionnaire was in English, but native-speaking assistants explained the questions and the task in the choice experiment to the LOs. To avoid any order effects, we randomized the order in which the choice experiment and survey was presented to the respondent.

\subsection{The data}

We surveyed in total 800 LOs. The study covered various geographical areas in Ethiopia: the city of Addis-Ababa and three largest regions (kilils): $\mathrm{SNNP}^{7}$ on the south, Oromia located in the central and eastern part of the country and Amhara on the north-west. The geographical breakdown of our study is shown in table 2. We surveyed LOs from 224 woredas (districts).

\footnotetext{
${ }^{6}$ We modified the choice experiment design in Sagamba et al. (2013) by removing three characteristics of family/household of the applicant, and adding the characterization of monthly savings.

${ }^{7}$ SNNP is the Southern Nations, Nationalities and People's Region
} 
Table 2: The Number of loan officers by region

\begin{tabular}{|c|c|}
\hline Region (kilil) & Number of LO \\
\hline \hline The city of Addis Ababa & 172 \\
\hline SNNP & 217 \\
\hline Oromia & 195 \\
\hline Amhara & 216 \\
\hline \hline Total & 800 \\
\hline
\end{tabular}

The survey covers 8 MFIs with diverse characteristics. MFIs are of different size, and they vary in geographical cover. ${ }^{8}$ Below we provide a general sample description.

In our sample, $80 \%$ of the surveyed LOs were men, which reflects the gender composition of LOs in Ethiopia. Almost all of the LOs are between 20 and 39 years old, more precisely, $59 \%$ are of age $20-29$, and $36 \%$ are $30-39$ age old. Most of the LOs have a high school diploma (67\%), and 16\% have a university diploma. Only 16\% LOs have not completed high school. The majority of LOs are very experienced in microfinance: $39 \%$ have worked in microfinance for more than 5 years, and $21 \%$ for 3 to 5 years. The remaining $40 \%$ have worked for less than 3 years. LOs tend to stick to one MFI: about $90 \%$ of LOs have always worked in the same MFI. See Appendix D.1 for details.

\subsection{Preferences of Loan Officer over Loan Allocation: Em- pirical Model}

The main tool for the analysis of the preferences of LOs over loan applicants, determining microloan allocation, is the choice experiment methodology. We follow Sagamba et al. (2013), but extend their investigation and put specific focus on the role of monitoring and initial savings of applicants.

Consider an LO deciding on whether to grant (or to recommend granting) a microloan to an applicant with some project. ${ }^{9}$ In this decision the LO takes

\footnotetext{
${ }^{8}$ For example, Wisdom covers the whole of Ethiopia while other MFIs such as OMO are concentrated in a single region.

${ }^{9}$ The final decision on microloan allocation is made by some committee, not by the LO
} 
into account two groups of factors: characteristics of the project and characteristics of the applicant. Let us denote the values of these factors for applicant $i$ by $x_{i}=\left(x_{i 1}, x_{i 2}, \ldots, x_{i K}\right)$. Additionally, the personality of the LO together with environment in which he/she operates, which in turn is determined by the incentives provided to the LO by MFI and his/her alignment with MFI mission/perceived objectives, influence the decision. Let us denote these additional factors influencing LO $j$ by $z_{j}=\left(z_{j 1}, \ldots, z_{j L}\right)$. There is also a random component $\varepsilon_{i j}$. The above mentioned factors determine the subjective benefit $u$ of LO $j$ from allocating a microloan to an applicant $i$ :

$$
u_{j i}=f\left(x_{i}, z_{j}, \varepsilon_{i j}\right)
$$

We further assume that the function $f$ is linear in the applicant's and project's characteristics $x_{i}$ with coefficients that can be LO-specific and are determined by the LO personality and environment, and that the random component is additive:

$$
u_{j i}=\sum_{k=1}^{K} \beta_{k}\left(z_{j}\right) x_{i k}+\varepsilon_{i j}
$$

The LO is presented with a pair of applicants and should decide which one he/she prefers. The decision is based on the comparison of the subjective utilities from allocating microloan to either of the two applicants $u_{j 1}$ and $u_{j 2}$. The probability that applicant 1 is preferred to applicant 2 by the LO $j$ is, therefore, given by $P=\operatorname{Prob}\left(\sum_{k=1}^{K} \beta_{k}\left(z_{j}\right) x_{1 k}+\varepsilon_{1 j} \geq \sum_{k=1}^{K} \beta_{k}\left(z_{j}\right) x_{2 k}+\varepsilon_{2 j}\right)$.

For the purpose of the choice experiment, the variables $x_{i k}$ are chosen to be categorical, so that each variable $x_{i k}$ can take values $c=1,2, \ldots, C_{k}$. See table 3.1 for the list of values of each variable. To study the impact of LO-specific (or environment specific) components on the preferences of the LO, the coefficients $\beta$ are decomposed into population-common component $\bar{\beta}$ and officer-specific (or environment-specific) component $\widetilde{\beta}: \beta=\bar{\beta}+\widetilde{\beta}(\widetilde{\beta}=0$ for those LOs for whom personally. However, the LO is much better informed about the applicant, and because of this the decision is based on the recommendation of LO. Deviations are rare. 
the feature of the environment under investigation is not present). Consequently, the estimated econometric specification for the choice experiment is

$$
u_{j i}=\sum_{k=1}^{7} \sum_{c=1}^{C_{k}} \bar{\beta}_{k c} I_{x_{i k}=c}+\sum_{k=1}^{7} \sum_{c=1}^{C_{k}} \widetilde{\beta}_{k c} I_{x_{i k}=c}+\varepsilon_{j i}
$$

\subsection{Estimation procedure}

In order to estimate the empirical model in (2), we use the alternative-specific conditional logit model (also known as McFadden's choice model - see McFadden (1974)). As standard, it is assumed that errors $\varepsilon_{j i}$ have a Gumbel distribution. In the main estimations it is assumed that errors $\varepsilon_{j i}$ are clustered across officers. As robustness checks, we re-estimate the same models under assumptions that standard errors are not clustered, by using robust White estimator and by using bootstrap.

\section{The Monitoring Process}

In this part we provide an analysis of the components of monitoring in Ethiopian MFIs and the role of LO in the process of monitoring.

\subsection{Monitoring is more than Inspection}

Monitoring is commonly perceived as mere inspection of the state of a borrower's enterprise with the purpose of reducing moral hazard and ensuring timely repayment.

While on-site inspection is an important part of monitoring activities in microfinance, this interaction between the LO and a borrower is not limited to inspection. According to our findings, $80 \%$ of LOs give advice on running the enterprise, $78 \%$ check the physical state of the enterprise, $70 \%$ advise on budgeting, $68 \%$ discuss plans for the future with the borrower and $51 \%$ check accounting records (see Appendix D.2). Although checking accounting records and the physical state of the enterprise can be considered instances of pure 
inspection, all other above mentioned activities are beyond the scope of pure inspection. Moreover, our results indicate that advising a borrower is as frequent as pure inspection activities. This is due to LOs being proficient in many aspects of the organization of entrepreneurial activity, such as bookkeeping, organizing production, marketing and sales; more than $70 \%$ reported that they have a high degree of competence in bookkeeping, organizing production and finding clients for a microenterprise, $60 \%$ are highly competent in finding sales possibilities, and $48 \%$ are highly competent in buying equipment for a microenterprise. ${ }^{10}$ This general provision of advice leads to a broad communication and the LO acquiring intimate knowledge of the borrower and the enterprise conducive to the emergence of close relationships.

The monitoring process is an important constituent of the relationship between an MFI and a borrower. The LO is the key element in this relationship because the LO collects and transmits information about the borrower to the MFI. Furthermore, the LO can moderate which part of the collected information will be passed on to the MFI. Therefore, MFI knowledge about the borrower is determined both by (i) the quality of information obtained by LO during monitoring, and (ii) by the LO's willingness to transmit this information to the MFI; its knowledge in this regard is subject to the discretion of the LO. We investigated in detail these two aspects of information transmission in microfinance.

First, we studied what makes monitoring more difficult. According to our findings, the two main factors are the distance to the borrower's enterprise and the time necessary for monitoring. Respectively, $54 \%$ and $53 \%$ of LOs assessed the importance of these factors as either 5 or 6 on a scale from 1 to 6 . A slightly less important factor is the non-cooperativeness of the borrower, as only $41 \%$ of LOs assessed it as 5 or 6 (see Appendix D.2). These results suggest that monitoring difficulty in Ethiopia can be attributed primarily to geographical

\footnotetext{
${ }^{10}$ The answers for every competence were given on a scale from 1 to 6 , where 1 corresponds to "not at all competent", and 6 to "very competent". We interpreted 5 and 6 as high competence. See details in Appendix D.1.
} 
factors or the complexity of an entrepreneurial project but also borrowers' lack of cooperation. This is consistent with LOs devoting a large amount of time to monitoring.

Second, we studied factors determining the LO's willingness to transmit information about a borrower's project to the MFI. This is the subject of the next section.

\subsection{Discretion of Loan Officers}

We presume that a major determinant of the LO's willingness to transmit information to the MFI, is the alignment of LO's views on microfinance with the perceived objectives of the MFI. We found that about one third of LOs (30\%) reported that their own views are fully aligned with their perception of their MFI's objectives; another third (34\%) reported that their own views are strongly aligned; $20 \%$ reported that their views are in general aligned; $17 \%$ reported that their views are more or less aligned. We also found that $70 \%$ of LOs perceive helping the poor as the main objective of their MFI. Others perceived the main objective of the MFI to be supporting women (6\%), achieving financial sustainability (13\%), or making profit (6\%). See Appendix D.4 for details.

The scope for the LO to exercise discretion is related to the soft nature of information. Indeed, the MFI cannot verify the state of an enterprise without the aid of an LO. Difficulties with the running of an entrepreneurial project or even violations of loan usage rules might be revealed during monitoring. In such an instance, the LO is supposed to report these issues to the MFI. Especially following a serious violation of loan usage, sanctions should be imposed on the borrower, according to the rules of microloan provision. For the MFI, a report from the LO is virtually the only way to learn about the borrower's issues. The LO, however, can postpone reporting, providing the borrower with some additional wiggle-room, or even decide not to report at all.

We found that exercising some degree of discretion is very common among LOs. Only $25 \%$ of LOs report immediately when a minor problem is detected 
(such as a delay with repayment of a farmer due to bad weather conditions), and $33 \%$ report immediately in case of a more serious problem that requires the imposition of a sanction. ${ }^{11}$ At the same time, most LOs exercise only a limited degree of discretion, such as postponing reporting to give a borrower some additional time to overcome the problem; $51 \%$ of LOs postpone reporting for a minor problem, and $42 \%$ for a more serious violation. Finally, a substantial number of LOs (25\%) exercise quite a strong degree of discretion, i.e., they do not report any minor problem; 19\% do not even report more serious violations (see Appendix D.3). These results confirm the significance of the LOs discretion for MFI knowledge of the borrower.

\section{Empirical Results}

\subsection{Preferences over Loan Allocation}

We first report the result of the baseline estimation. We estimate equation (3).

$$
u_{j i}=\sum_{k=1}^{7} \sum_{c=1}^{C_{k}} \bar{\beta}_{k c} I_{x_{i k}=c}+\sum_{k=1}^{7} \sum_{c=1}^{C_{k}} \widetilde{\beta}_{k c} I_{x_{i k}=c}+\varepsilon_{j i}
$$

Average marginal effects corresponding to coefficients are reported in Table 3, detailed results of estimations are provided in Appendix A

\subsubsection{Socially desirable groups}

Women have a $6 \%$ higher chance of being allocated a microloan, holding other things equal. This is consistent with the pro-social mission of microfinance, reflecting the aim of empowering women. Age has a non-monotone effect on the likelihood of being attributed a loan. Older applicants are preferred to younger up to the age of about 30 , but for older applicants, the likelihood of obtaining a microloan declines; an 18-year old applicant has a $5 \%$ lower chance than a 27 year old, and a 44-year old applicant has a 7\% lower chance. A similar pattern

\footnotetext{
${ }^{11}$ The problem is minor when its detection requires only reporting to MFI, without immediate sanction imposition.
} 
Table 3: Marginal Effects for the Pooled Estimation.

\begin{tabular}{c|c}
\hline \hline & $\mathrm{dp} / \mathrm{dx}$ \\
\hline age: 22 & $.044^{* * *}$ \\
\hline age: 27 & $.052^{* * *}$ \\
\hline age: 34 & $.030^{* * *}$ \\
\hline age: 44 & $-.022^{* *}$ \\
\hline gender: male & $-.058^{* * *}$ \\
\hline poverty: very poor & -.002 \\
\hline poverty: poor & $.016^{* *}$ \\
\hline prob2 & $.069^{* * *}$ \\
\hline prob3 & $.152^{* * *}$ \\
\hline prob4 & $.178^{* * *}$ \\
\hline loan size: medium & -.009 \\
\hline loan size: large & $-.056^{* * *}$ \\
\hline monitoring: with some difficulties & $-.018^{* * *}$ \\
\hline savings: slightly more than required & $.063^{* * *}$ \\
\hline savings: much more than required & $.078^{* * *}$ \\
\hline
\end{tabular}

was found in Sagamba et al. (2013), which, on the one hand, constitutes a deviation from the pro-social mission of microfinace, as the most needy are the youngest and the oldest. On the other hand, this contributes to the stability of the MFI by providing more loans to more experienced applicants.

The poverty level of the applicant is relevant to the allocation decision only at high levels of poverty; extremely poor applicants have a $1.6 \%$ lower chance of obtaining a microloan, holding other things equal.

Ethiopian legislation requires all applicants for a microloan to accumulate a certain amount of savings in an MFI-held savings account. Applicants with savings slightly more than required have a $6 \%$ greater chance of being allocated a loan, and applicants with much greater savings have an $8 \%$ greater chance than those who only meet the minimal savings requirement. The results of the choice experiment suggest, therefore, that LOs are sensitive to the amount of savings and favor applicants having savings above the minimal requirement. However, the magnitude of the additional savings is not of great importance. By acquiring more than only the minimal savings requirement, an applicant might signal her 
quality to the $\mathrm{LO}$ in terms of being able to exercise financial discipline and delay gratification from more immediate consumption choices. Such an interpretation is in line with the hyperbolic discounting literature on consumption vs. savings choices (see e.g., Fredericks et al., (2000) for an overview, or Laibson (1997)).

\subsubsection{Project Characteristics}

The two most important determinants of microloan attribution among all investigated characteristics of an applicant and project are (i) the probability of timely reimbursement - interpreted as indicative of the quality of the project and (ii) the difficulty of monitoring. The overall quality of the project characterized by the perceived probability of repayments delays is of great importance for LOs; a project with a $50 \%$ probability of repayment delays has an $18 \%$ lower chance of approval than a project which has almost no risk of repayment delays. Similarly, LOs are very sensitive to the difficulty of monitoring of the project; a project which is difficult to monitor has a $13 \%$ lower chance than an easy to monitor project.

Finally, the size of the loan for the project is also an important determinant of LOs' preferences for microloan allocation. Those applicants requesting larger loans have a lower chance as compared to those requesting smaller loans; the chances for obtaining a loan decreases by $6 \%$ for for a big loan as compared to a small loan. ${ }^{12}$

\subsection{Monitoring}

\subsubsection{Monitoring and Incentives}

In the baseline estimation we find that higher levels of monitoring difficulty are associated with smaller chances of being allocated a loan. Here we turn our attention to the different incentives provided to the $\mathrm{LO}$ and the interaction of these incentives with the importance assigned to monitoring difficulty in LO preferences.

\footnotetext{
${ }^{12}$ See Table 3 for details on the sizes of big and small loans.
} 
Our study asks respondents to indicate which of five kinds of incentives are provided to them. These incentives are rewards for: 1) lending more money; 2) providing more loans (outreach); 3) timely reimbursement; 4) providing loans to the poorest; 5) providing more loans to women. In the subsequent analysis, we introduce indicator variables for the provision of each type of incentives in the econometric model and estimate a model of the form (1). Detailed results are provided in Appendix B and we summarize the results related to monitoring in Table 4.

Table 4: The effect of incentive provision on the valuation of monitoring difficulty.

\begin{tabular}{|l|c|c|c|c|c|}
\hline & \multicolumn{5}{|c|}{ Incentive type } \\
\hline & 1 & 2 & 3 & 4 & 5 \\
\hline $\begin{array}{l}\text { Intermediate monitoring } \\
\text { difficulty }\end{array}$ & -0.03 & -0.04 & -0.02 & -0.09 & 0.01 \\
\hline $\begin{array}{l}\text { Highest monitoring diffi- } \\
\text { culty }\end{array}$ & $-0.17^{* * *}$ & $-0.15^{* * *}$ & -0.09 & $-0.15^{* *}$ & -0.05 \\
\hline
\end{tabular}

Note: The baseline is easy to monitor projects. The incentive types are $1=$ Sum of money, $2=$ Number of loans (outreach), $3=$ Timely reimbursement, $4=$ Loans to the poorest, $5=$ Loans to women

The strongest effects are found when LOs are either provided incentives to maximize the sum of money lent (1), maximizing the number of loans (2) or providing loans to the poorest (4). The provision of these incentives makes LOs more sensitive to the difficulty of monitoring; the high level of monitoring difficulty decreases the probability of being allocated a loan by $15-17 \%$. These effects are present only for projects with high monitoring difficulty but not for projects with intermediate monitoring difficulty.

From the analysis of the estimation results presented in Appendix B, one can notice that the provision of certain incentives - based on the sum of disbursed funds and timely reimbursement - influences only the importance assigned to monitoring difficulty. When outreach is incentivized, the importance assigned to monitoring difficulty and probability of timely reimbursements are affected. These observations further motivate paying particular attention to these two factors in studying the role of LOs in microfinance institutions. 


\subsubsection{Monitoring and Mission Perception/Alignment with the Mis- sion}

We presume that the importance the LO assigns to monitoring difficulty will depend on the perceived aims of the MFI; there is a basic trade-off between the perceived aims of the MFI and monitoring difficulty. For instance, if the aim of the MFI is helping the poor which are known to be harder to monitor, LOs will have to assign less importance to monitoring difficulty. Otherwise it would be impossible to help the poor. On the other hand, if the perceived aim of the MFI is to make profit, the LO ought to avoid difficult to monitor projects because difficult to monitor projects imply taking more financial risks.

We ask respondents to provide their views on what they perceive is the mission of their own MFI and we analyse how mission perception interacts with the importance assigned to monitoring difficulty. First we ask respondents what they perceive as the main aim of their respective MFIs and second we ask about all the objectives their MFI. We found that the importance assigned to monitoring difficulty by LOs varies among MFIs with different missions (as perceived by microloan officers). A summary of the results is provided in Tables 5 and 6 (for detailed estimation results see Appendix C). Technically, we split the sample into subsamples based on each of the four possible aims and estimated models of the form in (1). The coefficients $\beta$ show the changes in the importance assigned to monitoring difficulty by LOs in MFIs with certain (perceived) aims are reported in tables 5 and 6 . All the significant effects pertain to the projects with high monitoring difficulty.

Table 5: Effect of perceived mission of MFI on the importance assigned to monitoring difficulty.

\begin{tabular}{|l|c|c|c|c|}
\hline & \multicolumn{4}{|c|}{ Mission perception (one of the aims) } \\
\hline & $\begin{array}{l}\text { Support } \\
\text { poor }\end{array}$ & $\begin{array}{l}\text { Support } \\
\text { women }\end{array}$ & $\begin{array}{l}\text { Making } \\
\text { profit }\end{array}$ & $\begin{array}{l}\text { Financial } \\
\text { stability }\end{array}$ \\
\hline $\begin{array}{l}\text { Intermediate monitoring } \\
\text { difficulty }\end{array}$ & -0.15 & -0.07 & -0.02 & 0.02 \\
\hline High monitoring difficulty & $-0.34^{* * *}$ & 0.08 & 0.01 & -0.07 \\
\hline
\end{tabular}


Table 6: Effect of perceived mission of MFI on the importance assigned to monitoring difficulty.

\begin{tabular}{|l|c|c|c|c|}
\hline & \multicolumn{3}{|c|}{ Mission perception (the main aim) } \\
\hline & $\begin{array}{l}\text { Support } \\
\text { poor }\end{array}$ & $\begin{array}{l}\text { Support } \\
\text { women }\end{array}$ & $\begin{array}{l}\text { Making } \\
\text { profit }\end{array}$ & $\begin{array}{l}\text { Financial } \\
\text { stability }\end{array}$ \\
\hline $\begin{array}{l}\text { Intermediate monitoring } \\
\text { difficulty }\end{array}$ & -0.05 & -0.12 & 0.08 & 0.09 \\
\hline High monitoring difficulty & $-0.12^{*}$ & 0.06 & $0.18^{*}$ & 0.01 \\
\hline
\end{tabular}

LOs who perceive as an aim of their MFIs supporting the poor assign a lower importance to the difficulty of monitoring while those who perceive the aim as making profit, assign a higher importance to the difficulty of monitoring. We did not find statistically significant effects of other aims on the importance assigned to monitoring difficulty.

\subsubsection{Discretion of Loan Officers During Monitoring}

This section examines the relationship between LO discretion and importance assigned to monitoring difficulty. The necessity to report is associated with relatively mild difficulties in running the borrower's enterprise, while the necessity to impose a sanction is associated with relatively serious problem, or violations of the loan use conditions. We therefore ask respondents to rate to what extent they exercise discretion. ${ }^{13}$ We first examine the impact of different degrees of discretion in reporting on the importance assigned to monitoring difficulty. Technically, we reestimate the model of the form in (1) on subsamples corresponding to different degrees of discretion and focus on the changes in importance assigned to monitoring of difficulty between the subsamples. The results are summarized in table 7 , and detailed estimation results are presented in Appendix E.

The effect of intermediate monitoring difficulty seems to vary with level of discretion in reporting. For low levels of discretion (1 and 2), intermediate difficulty does not seem to have any effect. As the level of discretion in reporting

\footnotetext{
${ }^{13}$ We used a scale from 1 to 4 , where 1 means "reporting/imposing sanction immediately," i.e., minimal discretion and 4 means "you often take decisions on your own even when the guidelines prescribe to do something else," i.e., the highest degree of discretion.
} 
Table 7: Effect of discretion in reporting on the importance assigned to monitoring difficulty

\begin{tabular}{|l|c|c|}
\hline & \multicolumn{2}{|c|}{ Discretion in reporting } \\
\hline & 1 and 2 & 3 and 4 \\
\hline Intermediate monitoring difficulty & -0.01 & $-0.08^{* *}$ \\
\hline High monitoring difficulty & $-0.51^{* * *}$ & $-0.54^{* * *}$ \\
\hline
\end{tabular}

Note: $1=$ minimal level of discretion; $4=$ maximum level of discretion.

increases, however, so does the importance assigned to intermediate difficulty. For high levels of discretion (3 and 4), the negative effect increases from - 0.01 to -0.08 . When it comes the the high level of monitoring difficulty the effect is generally large and negative.

We repeat this exercise for our measure of discretion in sanctioning and detailed results are provided in Appendix E. As before, we summarize our results related to monitoring in Table 8.

Table 8: Effect of discretion in sanctioning on the importance assigned to monitoring difficulty

\begin{tabular}{|l|c|c|}
\hline & \multicolumn{2}{|c|}{ Discretion in sanctioning } \\
\hline & 1 and 2 & 3 and 4 \\
\hline Intermediate monitoring difficulty & -0.02 & $-0.12^{* * *}$ \\
\hline High monitoring difficulty & $-0.54^{* * *}$ & $-0.53^{* * *}$ \\
\hline
\end{tabular}

Note: $1=$ minimal level of discretion; $4=$ maximum level of discretion.

The effect of intermediate monitoring difficulty seems to vary with level of discretion in sanctioning. For low levels of discretion (1 and 2), intermediate difficulty does not seem to have any effect. As the level of discretion in sanctioning increases, however, so does the importance assigned to intermediate difficulty. For high levels of discretion (3 and 4), the negative effect increases from -0.02 to -0.12 . When it comes the the high level of monitoring difficulty the effect is generally large and negative.

In general, our results indicate that LOs who exercise more discretion in reporting or sanctioning also assign greater importance to monitoring difficulty and are more likely to avoid hard to monitor projects. 


\subsection{Clients savings}

\subsubsection{Savings and incentives}

Here we again turn our attention to the different incentives provided to the LO and the interaction of the incentives provided with the importance assigned to client savings. In the baseline estimation we find that higher levels of savings are associated with higher chances of being allocated a loan. In subsequent analysis, we introduce indicator variables for the provision of each type of incentive and estimate a model of the form in (2). Detailed results are provided in Appendix $\mathrm{B}$ and we summarize the results related to savings in Table 9.

Table 9: Effect of incentive provision on the importance assigned to savings level

\begin{tabular}{|l|c|c|c|c|c|}
\hline & \multicolumn{5}{|c|}{ Incentive type } \\
\hline $\begin{array}{l}\text { Slightly more than compulsory } \\
\text { savings }\end{array}$ & 0.05 & -0.02 & -0.2 & -0.02 & $-0.10^{*}$ \\
\hline $\begin{array}{l}\text { Savings much more than compul- } \\
\text { sory }\end{array}$ & -0.03 & -0.04 & -0.00 & $-0.12^{*}$ & $-0.15^{* *}$ \\
\hline
\end{tabular}

Note: The incentive types are $1=$ Sum of money, $2=$ Number of loans (outreach),

$3=$ Timely reimbursement, $4=$ Loans to the poorest, $5=$ Loans to women

The strongest results are found for those LOs who state that they have an incentive to provide loans to women (5). While higher than required savings are associated with a higher valuation of an applicant's project, being incentivized to provide loans to women reduces the importance assigned to additional savings. A similar, but weaker result is obtained for those who are incentivized to provide loans to the poorest (4). Taken together, these results are inline with the prosocial mission of microfinance.

\subsubsection{Savings and Mission Perception/Alignment with the Mission}

We found that importance assigned to savings level by LOs varies among MFIs with different missions (as perceived by LOs) and a summary of the results is provided in Tables 10 and 11 (for detailed estimation results see Appendix C). Technically, we split the sample into subsamples based on each of the four 
possible aims and estimated models of the form (1). The coefficients $\beta$ show the importance assigned to savings level by perceived aim are reported in tables 10 and 11 .

For those who perceive the mission to be supporting women, the coefficient is negative, indicating that these LOs assign less importance to savings level. This is to be expected if women are those who usually have a harder time producing higher than required savings levels. On the other hand, for those who perceive the mission to be making profit or maintaining financial sustainability, additional savings much above the required minimum, increases importance assigned to savings. Although slightly weaker statistically, a similar pattern emerges when we repeat the analysis by the perceived main aim of the MFI (Table 11).

Table 10: The importance assigned to savings level by mission perception.

\begin{tabular}{|l|c|c|c|c|}
\hline & \multicolumn{3}{|c|}{ Mission perception (one of the aims) } \\
\hline & $\begin{array}{l}\text { Support } \\
\text { poor }\end{array}$ & $\begin{array}{l}\text { Support } \\
\text { women }\end{array}$ & $\begin{array}{l}\text { Making } \\
\text { profit }\end{array}$ & $\begin{array}{l}\text { Financial } \\
\text { stability }\end{array}$ \\
\hline $\begin{array}{l}\text { Slightly more than com- } \\
\text { pulsory savings }\end{array}$ & 0.1 & -0.09 & 0.09 & 0.07 \\
\hline $\begin{array}{l}\text { Much more than compul- } \\
\text { sory savings }\end{array}$ & 0.02 & $-0.16^{* *}$ & $0.11^{*}$ & $0.16^{* * *}$ \\
\hline
\end{tabular}

Table 11: The importance assigned to savings level by mission perception.

\begin{tabular}{|l|c|c|c|c|}
\hline & \multicolumn{4}{|c|}{ Mission perception (the main aim) } \\
\hline & $\begin{array}{l}\text { Support } \\
\text { poor }\end{array}$ & $\begin{array}{l}\text { Support } \\
\text { women }\end{array}$ & $\begin{array}{l}\text { Making } \\
\text { profit }\end{array}$ & $\begin{array}{l}\text { Financial } \\
\text { stability }\end{array}$ \\
\hline $\begin{array}{l}\text { Savings slightly more } \\
\text { than compulsory }\end{array}$ & -0.02 & -0.04 & -0.05 & 0.12 \\
\hline $\begin{array}{l}\text { Savings much more than } \\
\text { compulsory }\end{array}$ & -0.08 & $-0.27^{*}$ & 0.12 & $0.18^{*}$ \\
\hline
\end{tabular}

As in the case with monitoring difficulty and mission perception, there is a basic trade-off between perceived mission and the importance assigned to savings. Those who perceive the mission to be supporting women assign less importance to applicants with larger savings. This could be an indication of favouritism of women as men more frequently hold larger savings. Indeed, our result indicate that LOs dislike applicants with larger savings. 
On the other hand, those who perceive the aim as financial stability, assign higher importance to high levels of savings; higher savings might indicate better financial discipline of the applicant.

\section{Implications for MFI governance}

Loan officers constitute an important link between the MFI and the individual borrower. Through loan allocation, LOs determine the portfolio of clients and thereby determine the success of MFIs in terms of financial sustainability and achieving social goals. LO preferences over loan allocation are therefore critical. MFIs can, however, influence LO choices through incentive provision and LOs' perception of organizational aims and priorities.

Our results have implications for MFI governance. While all MFIs exhibit concern for both financial viability and social goals, there is considerable variation in priorities between the two. Loan officers are critical for implementation of a given aim of an MFI. Organizational features, such as incentives, determine the success in accomplishing MFI aims by influencing LO allocation decisions. We find, however, that straightforward attempts to steer loan allocation in favor of socially desirable groups do not always have the intended effect.

Our results suggest a number of recommendations for those MFIs that prioritise loan provision to women. In this case, our results indicate that straightforward policies will likely be effective. First, these MFIs can incentivise LOs to provide more loans to female applicants. Second, they can direct additional efforts to conveying this aim to LOs, as those who perceive that supporting women is an MFI aim exhibit stronger preferences for allocating loans to women. These strategies, however, may have indirect effects that warrant further attention and ought to be taken into account. For instance, when LOs perceive that providing loans to women as an aim, or when they are provided with an incentive to allocate more loans to women, they also start paying less attention to the savings of the applicant. This may be desirable, as women in developing countries usually 
have less savings than men, but may also jeopardize the financial viability of the MFI.

For MFIs that prioritise supporting the poor, our recommendations are more modest. We do not find a significant direct effect of incentives to provide loans to the poor, although the effect is in the right direction. This incentive may work, but we have found only weak evidence in its support. On the other hand, an MFI can better reach its target group by convincingly conveying its aim to LOs. This benefit is especially large when the LO perceives helping the poor as the main aim of the MFI, as opposed to when it is one of the perceived aims. MFIs should therefore narrowly frame their mission statement as supporting the poor. These strategies, however, may also have unintended consequences. LOs provided with incentives to allocate more loans to the poor, or who perceive the aim as supporting the poor, pay less attention to the savings of the applicant, and discriminate more against projects that are difficult to monitor. These effects ought to be taken into account when designing incentives for a particular MFI.

Finally, our results also imply recommendations for MFIs that prioritise financial stability. We find that providing additional incentives to LOs for higher reimbursement rates does not seem to have any effect on prioritising projects with higher chances of timely reimbursement. On the other hand, we find some evidence that, when the aim of the MFI is perceived as making profit or as financial stability, LOs do prioritize projects with higher chances of timely reimbursement. In addition, LOs will prioritise applicants with larger amounts of savings if they perceive that the aim is to make profit or achieve financial sustainability. MFIs prioritising financial stability should therefore focus on clearly conveying this aim to their LOs rather than providing incentives. 


\section{Conclusion}

Loan officers play an important intermediary role in the relationship between MFIs and borrowers and in this way determine the success of financial intermediation between donors and the financially constrained poor in the developing world. We studied LO preferences over loan allocation and how these preferences interact with both incentives and the perceived aim of the MFI. We generally found that LOs pay attention both to borrower characteristics related to prosocial aims and to the characteristics of the project that relate to the financial sustainability of the MFI. Our results also show that MFIs can indeed influence LOs' allocation decisions through incentive provision and by emphasizing organizational aims.

The most important determinants of loan allocation are those related to the financial viability of MFIs, such as the quality of the project as measured by the probability of repayment delays and difficulty of monitoring. Characteristics related to pro-social aims, such as gender and poverty, play a significant but lesser role. In addition, applicants with savings above the minimal required level are given priority.

We found that, generally, incentives provided by the MFI influence LOs' allocation decisions. Those incentives that target specific characteristics of an applicant, such as gender or poverty level, seem to influence allocation decisions in the intended direction. For most incentives, we found an additional negative effect on projects that are difficult to monitor. In addition, when LOs are incentivized to provide loans to the poorest or to women, they pay less attention to the level of savings of an applicant. We also found that the perceived aim of the MFI affects LOs' allocation decisions. We found that, when LOs perceive supporting the poor as the aim of the MFI, they tend to avoid allocating loans to those projects that are difficult to monitor. Those that perceive supporting women as the aim of the MFI pay less attention to savings level and those that perceive achieving financial stability as the aim pay more attention to savings. 
Finally, we found that LO discretion in reporting and sanctioning is important for the effect of monitoring difficulty in allocation decisions; more discretion is associated with an additional negative effect of monitoring difficulty.

The choice experimental methodology constitutes a novel approach to the study of microfinance. Commonly applied methodologies based on granted loans are notoriously problematic for the study of microfinance due to selection bias. Without any knowledge of applicants who are denied microloans, it is not possible to study what determines loan allocation. Although based on hypothetical choices, choice experimental methodology is a viable alternative. Successful financial intermediation by MFIs is in large part determined by the LOs and the decisions they make. Here, we have studied LO preferences for loan allocation and its relationship to organizational structure. On the basis of our analysis, we have developed recommendations specific to MFI objectives. Further exploration of the impact of other constraints on LO activities, such geographical proximity, might prove fruitful for improving financial intermediation and, ultimately, access to finance for the poor. 


\section{Appendix}

\section{A Pooled Regression}

Marginal Effects for the Pooled Estimation.

\begin{tabular}{ccccc}
\hline \hline & $\mathrm{dp} / \mathrm{dx}$ & $\mathrm{SE}$ & $\mathrm{z}$ & $P>|z|$ \\
\hline age2 & .0443 & .0093 & 4.765 & $1.9 \mathrm{e}-06$ \\
\hline age3 & .0519 & .0096 & 5.429 & $5.7 \mathrm{e}-08$ \\
\hline age4 & .0297 & .0096 & 3.089 & .002 \\
\hline gender & -.0221 & .0097 & -2.284 & .0223 \\
\hline pov2 & -.0576 & .005 & -11.53 & $9.1 \mathrm{e}-31$ \\
\hline pov3 & -.0016 & .007 & -.231 & .8173 \\
\hline prob2 & .016 & .0075 & 2.146 & .0319 \\
\hline prob3 & .0689 & .0087 & 7.928 & $2.2 \mathrm{e}-15$ \\
\hline prob4 & .152 & .0073 & 20.69 & $4.0 \mathrm{e}-95$ \\
\hline loan2 & .1781 & .0072 & 24.79 & $1 . \mathrm{e}-135$ \\
\hline loan3 & -.0094 & .007 & -1.337 & .1811 \\
\hline monit2 & -.0557 & .0067 & -8.341 & $7.4 \mathrm{e}-17$ \\
\hline monit3 & -.0181 & .0069 & -2.636 & .0084 \\
\hline savings2 & -.1271 & .0063 & -20.1 & $7.9 \mathrm{e}-90$ \\
\hline savings3 & .0633 & .0067 & 9.517 & $1.8 \mathrm{e}-21$ \\
\hline savings3 & .0781 & .0068 & 11.49 & $1.5 \mathrm{e}-30$ \\
\hline
\end{tabular}




\section{B Impact of incentives}

\begin{tabular}{|c|c|c|c|c|c|c|}
\hline Attribute & baseline & $\max$ sum & outreach & reimb. rate & poorest & women \\
\hline \multirow[t]{2}{*}{ age2 } & $.178^{* * *}$ & $.171^{* * *}$ & $.162^{* * *}$ & $.133^{* * *}$ & $.163^{* * *}$ & $.176^{* * *}$ \\
\hline & $(.038)$ & $(.043)$ & $(.046)$ & $(.044)$ & $(.042)$ & $(.044)$ \\
\hline \multirow[t]{2}{*}{ age3 } & $208 * * *$ & $.205^{* * *}$ & $221 * * *$ & $.213^{* * *}$ & $208^{* * *} *$ & $21^{* * *}$ \\
\hline & $(.039)$ & $(.044)$ & $(.047)$ & $(.046)$ & $(.043)$ & $(.045)$ \\
\hline \multirow[t]{2}{*}{ age 4} & $.119^{* * *}$ & $.154^{* * *}$ & $.167 * * *$ & $.109 * *$ & $.111^{* * *}$ & $.146^{* * *}$ \\
\hline & $(.039)$ & $(.044)$ & $(.047)$ & $(.046)$ & $(.043)$ & $(.045)$ \\
\hline \multirow[t]{2}{*}{ age 5} & $-.0884^{* *}$ & $-.108^{* *}$ & $-.117^{* *}$ & $-.129 * * *$ & $-.0978^{* *}$ & $-.0913^{* *}$ \\
\hline & $(.039)$ & $(.045)$ & $(.048)$ & $(.046)$ & $(.043)$ & $(.045)$ \\
\hline \multirow[t]{2}{*}{ gender } & $-.23^{* * *}$ & $-.217 * * *$ & $-.214^{* * *}$ & $-.233^{* * *}$ & $-.223 * * *$ & $-.209 * * *$ \\
\hline & $(.02)$ & $(.023)$ & $(.024)$ & $(.023)$ & $(.022)$ & $(.023)$ \\
\hline \multirow[t]{2}{*}{ poverty2 } & -.0064 & .0206 & .0261 & .014 & .0102 & -.0064 \\
\hline & $(.028)$ & $(.032)$ & $(.034)$ & $(.033)$ & $(.031)$ & $(.032)$ \\
\hline \multirow{2}{*}{ poverty3 } & $.064^{* *}$ & $.0764^{* *}$ & $.0694^{*}$ & $.0844^{* *}$ & $.083^{* *}$ & $.0397^{\sim}$ \\
\hline & $(.03)$ & $(.034)$ & $(.036)$ & $(.034)$ & $(.033)$ & $(.034)$ \\
\hline \multirow[t]{2}{*}{ prob2 } & $.277^{*} * *$ & $297 * * *$ & $.257 * * *$ & $.309^{* * *}$ & $.277^{* * *} *$ & $.283^{* * *}$ \\
\hline & $(.035)$ & $(.04)$ & $(.042)$ & $(.041)$ & $(.039)$ & $(.04)$ \\
\hline \multirow[t]{2}{*}{ prob3 } & $.631^{* * *}$ & $646^{* * *}$ & $.608 * * *$ & $.632^{* * *}$ & $.641^{* * *}$ & $.617 * * *$ \\
\hline & $(.033)$ & $(.038)$ & $(.041)$ & $(.039)$ & $(.037)$ & $(.039)$ \\
\hline \multirow[t]{2}{*}{ prob4 } & $.75 * * *$ & $.728^{* * *}$ & $.695 * * *$ & $.723^{* * *}$ & $.763^{* * *}$ & $.752^{* * *}$ \\
\hline & $(.034)$ & $(.039)$ & $(.041)$ & $(.04)$ & $(.037)$ & $(.039)$ \\
\hline \multirow[t]{2}{*}{ loan_size2 } & $-.0377^{\sim}$ & $-.0495^{\sim}$ & -.0269 & -.0332 & $-.0581^{*}$ & -.0363 \\
\hline & $(.028)$ & $(.032)$ & $(.034)$ & $(.033)$ & $(.031)$ & $(.032)$ \\
\hline \multirow[t]{2}{*}{ loan_size3 } & $-.223^{* * *}$ & $-.249 * * *$ & $-.221^{* * *}$ & $-.222 * * *$ & $-.235 * * *$ & $-.219 * * *$ \\
\hline & $(.027)$ & $(.031)$ & (.033) & $(.032)$ & $(.03)$ & $(.031)$ \\
\hline \multirow[t]{2}{*}{ monit2 } & $-.0726 * * *$ & $-.0653^{* *}$ & $-.0635^{*}$ & $-.0684^{* *}$ & $-.059 *$ & $-.0792^{* *}$ \\
\hline & $(.028)$ & $(.032)$ & $(.034)$ & $(.033)$ & $(.031)$ & $(.032)$ \\
\hline \multirow[t]{2}{*}{ monit3 } & $-.518 * * *$ & $-.479 * * *$ & $-.475 * * *$ & $-.497 * * *$ & $-.491 * * *$ & $-.511 * * *$ \\
\hline & $(.027)$ & $(.031)$ & $(.033)$ & $(.032)$ & $(.03)$ & $(.031)$ \\
\hline \multirow[t]{2}{*}{ savings 2} & $.255^{* * *}$ & $.244^{* * *}$ & $.266^{* * *}$ & $.261^{* * *}$ & $.257^{*} * *$ & $.28^{* * *}$ \\
\hline & $(.027)$ & $(.031)$ & $(.033)$ & $(.032)$ & $(.03)$ & $(.031)$ \\
\hline \multirow[t]{2}{*}{ savings3 } & $.316^{* * *}$ & $.328 * * *$ & $.335^{* * *}$ & $.319^{* * *}$ & $.34 * * *$ & $.357 * * *$ \\
\hline & $(.028)$ & $(.032)$ & $(.034)$ & $(.033)$ & $(.031)$ & $(.032)$ \\
\hline age $2 X$ & & .042 & .0475 & $.158^{*}$ & .0579 & .0016 \\
\hline & & $(.088)$ & $(.08)$ & $(.084)$ & (.099) & $(.087)$ \\
\hline age $3 X$ & & .023 & -.0451 & -.0182 & -.0332 & -.0071 \\
\hline & & $(.09)$ & $(.082)$ & $(.086)$ & $(.101)$ & $(.09)$ \\
\hline age $4 \mathrm{X}$ & & $-.138^{\sim}$ & $-.148^{*}$ & .0324 & $4.3 \mathrm{e}-04$ & $-.103^{\sim}$ \\
\hline & & $(.088)$ & $(.081)$ & $(.084)$ & $(.099)$ & $(.088)$ \\
\hline age $5 \mathrm{X}$ & & .0736 & .055 & $.13^{\sim}$ & .0152 & .0076 \\
\hline & & $(.09)$ & $(.082)$ & $(.086)$ & $(.1)$ & $(.09)$ \\
\hline gender $2 \mathrm{X}$ & & $-.0579^{\sim}$ & -.0448 & .007 & -.0468 & $-.0846^{*}$ \\
\hline & & $(.044)$ & $(.04)$ & $(.042)$ & $(.049)$ & $(.044)$ \\
\hline poverty2X & & $-.1^{\sim}$ & $-.0796^{\sim}$ & -.0622 & -.0753 & .0153 \\
\hline & & $(.061)$ & $(.056)$ & $(.058)$ & $(.068)$ & $(.061)$ \\
\hline poverty3X & & -.0562 & -.0108 & -.0693 & $-.106^{\sim}$ & $.0776^{\sim}$ \\
\hline & & $(.063)$ & $(.058)$ & $(.061)$ & $(.07)$ & $(.063)$ \\
\hline prob2X & & -.0859 & .0785 & $-.114^{\sim}$ & $-5.0 \mathrm{e}-04$ & .0142 \\
\hline & & $(.076)$ & $(.07)$ & $(.072)$ & $(.085)$ & $(.076)$ \\
\hline prob3X & & -.0519 & $.0938^{\sim}$ & .0047 & -.0289 & .0691 \\
\hline & & $(.075)$ & $(.069)$ & $(.071)$ & $(.083)$ & $(.075)$ \\
\hline prob4X & & $.102^{\sim}$ & $.185^{* * *}$ & $.109^{\sim}$ & -.0614 & .0309 \\
\hline & & $(.078)$ & $(.071)$ & $(.074)$ & $(.087)$ & $(.077)$ \\
\hline loan_size2X & & .0383 & -.0367 & -.021 & $.0852^{\sim}$ & -.0227 \\
\hline & & $(.062)$ & $(.057)$ & $(.059)$ & $(.069)$ & $(.061)$ \\
\hline loan_size3X & & $.094^{\sim}$ & -.0205 & -.0127 & .0477 & -.0337 \\
\hline & & $(.061)$ & $(.056)$ & $(.058)$ & $(.068)$ & $(.061)$ \\
\hline monit2X & & -.0343 & -.0372 & -.0194 & $-.0852^{\sim}$ & .0104 \\
\hline & & $(.063)$ & $(.057)$ & $(.06)$ & $(.069)$ & $(.062)$ \\
\hline
\end{tabular}




\begin{tabular}{ccccccc}
\hline Attribute & baseline & max sum & outreach & reimb. rate & poorest & women \\
\hline monit3X & & $-.173^{* * *}$ & $-.152^{* * *}$ & $-.0879^{\sim}$ & $-.151^{* *}$ & -.0471 \\
& & $(.063)$ & $(.057)$ & $(.06)$ & $(.07)$ & $(.062)$ \\
savings2X & & .0521 & -.0239 & -.0154 & -.0193 & $-.102^{*}$ \\
& & $(.062)$ & $(.056)$ & $(.059)$ & $(.068)$ & $(.061)$ \\
savings3X & & -.0276 & -.0381 & .0025 & $-.123^{*}$ & $-.15^{* *}$ \\
& & $(.062)$ & $(.057)$ & $(.06)$ & $(.069)$ & $(.062)$ \\
2 & & & & & & \\
_cons & $-.03^{\sim}$ & -.0281 & -.0265 & $-.0299^{\sim}$ & $-.0297^{\sim}$ & -.0269 \\
& $(.025)$ & $(.025)$ & $(.025)$ & $(.025)$ & $(.025)$ & $(.025)$
\end{tabular}




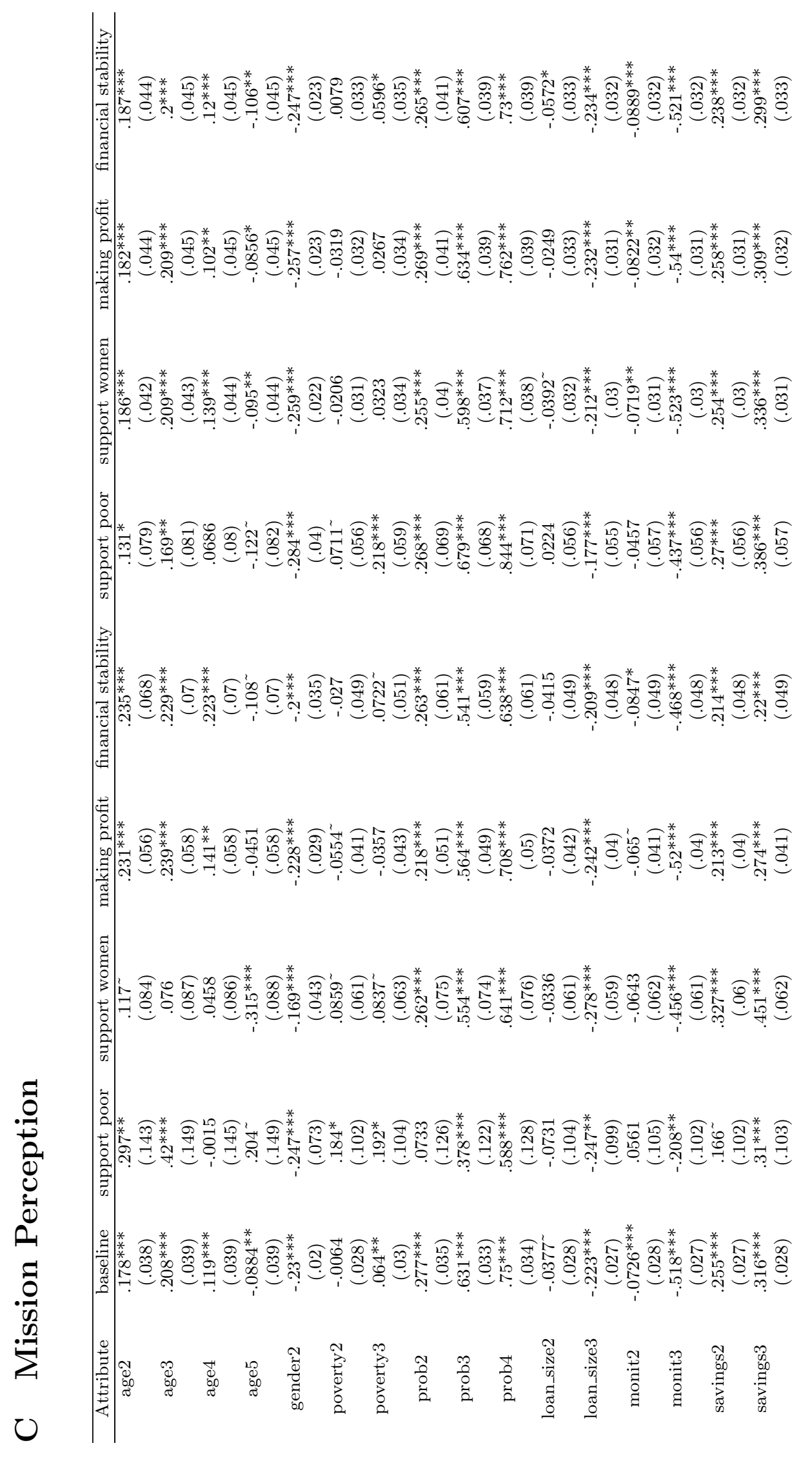




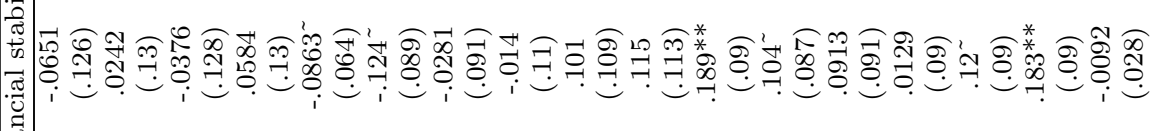

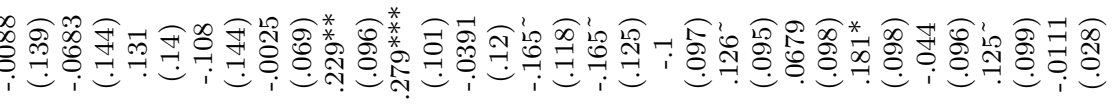

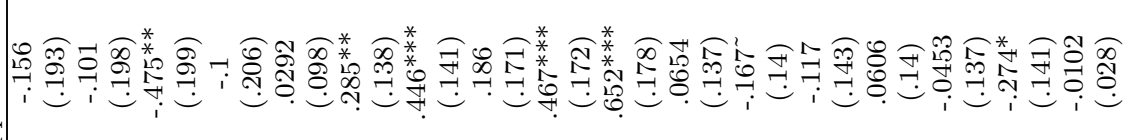

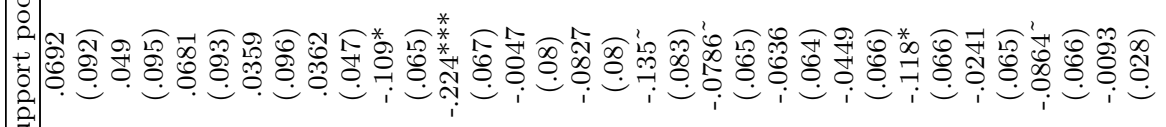

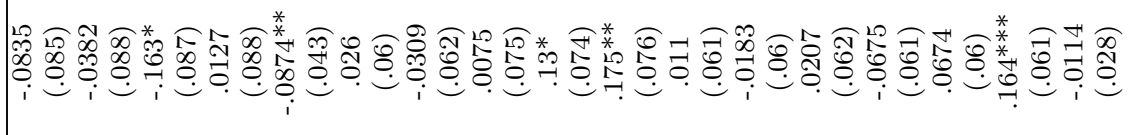

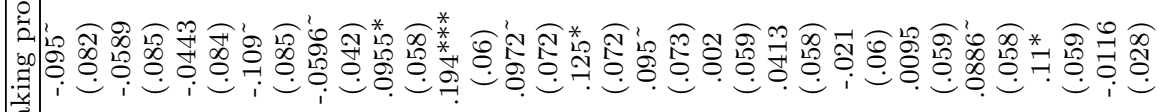

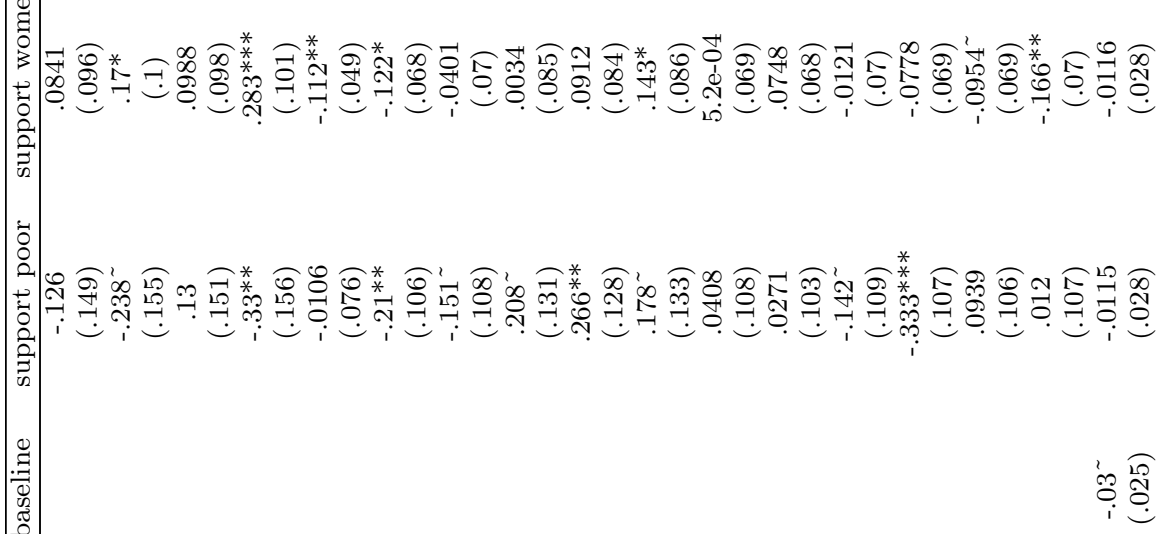

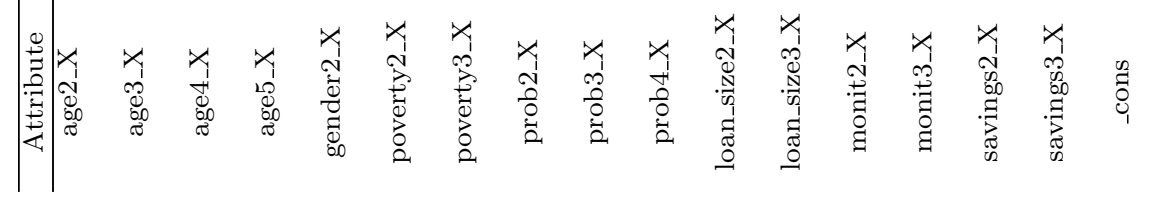




\section{Loan Officers, Monitoring and Discretion}

\section{D.1 Characteristics of Loan Officers}

\begin{tabular}{|c|c|c|}
\hline \multicolumn{3}{|c|}{ Gender of Loan Officers } \\
\hline & $N$ & Percentag \\
\hline Male & 627 & 80 \\
\hline Female & 156 & 20 \\
\hline Total & 783 & 100 \\
\hline \multicolumn{3}{|c|}{ Age of Loan Officers } \\
\hline Item & $\bar{N}$ & Percentage \\
\hline$\leq 19$ & 7 & 1 \\
\hline $20-29$ & 469 & 59 \\
\hline $30-39$ & 287 & 36 \\
\hline $40-49$ & 33 & 4 \\
\hline$\geq 50$ & 1 & 0 \\
\hline Total & 797 & 100 \\
\hline
\end{tabular}

\begin{tabular}{lrr}
\hline \multicolumn{3}{c}{ The highest level of education attained } \\
\hline Secondary incomplete & $N$ & Percentage \\
Secondary school complete & 7 & 1 \\
TVET Certificate & 86 & 11 \\
Diploma & 33 & 4 \\
Higher education (4 years of University) & 528 & 67 \\
Masters Degree & 128 & 16 \\
Other & 1 & 0 \\
Total & 1 & 0 \\
\hline
\end{tabular}

Years of service in the MFI sector

\begin{tabular}{|c|c|c|c|c|c|c|c|c|}
\hline \multirow[t]{2}{*}{ in the MFI sector } & \multicolumn{5}{|c|}{ In the current MFI } & & & \\
\hline & $<1$ & \multicolumn{2}{|c|}{$1-2$} & $3-5$ & $5+$ & & & \\
\hline$<1$ & 91.37 & \multicolumn{2}{|c|}{6.47} & 0.72 & 1.44 & & & \\
\hline $1-2$ & 5.26 & \multicolumn{2}{|c|}{90.79} & 2.63 & 1.32 & & & \\
\hline $3-5$ & 6.02 & \multicolumn{2}{|c|}{4.22} & 85.54 & 4.22 & & & \\
\hline $5+$ & 3.04 & \multicolumn{2}{|c|}{3.34} & 3.95 & 89.67 & & & \\
\hline \multicolumn{9}{|c|}{ Proficiency of Loan officers } \\
\hline & & & \multicolumn{6}{|c|}{ Degree of proficiency } \\
\hline \multirow{2}{*}{\multicolumn{3}{|c|}{ bookkeeping }} & 1 & 2 & 3 & 4 & 5 & 6 \\
\hline & & & 0.38 & 0.88 & 4.25 & 18.25 & 37.88 & 38.38 \\
\hline \multicolumn{3}{|c|}{ organization of production process } & 0.88 & 1.38 & 5.39 & 17.04 & 41.35 & 33.96 \\
\hline \multicolumn{3}{|c|}{ selling } & 3.75 & 4.38 & 8.39 & 23.15 & 37.55 & 22.78 \\
\hline \multicolumn{3}{|c|}{ find clients } & 2.13 & 1.63 & 4.39 & 16.06 & 34.38 & 41.41 \\
\hline \multicolumn{3}{|c|}{ buying equipment } & 9.72 & 6.19 & 12.37 & 23.48 & 29.55 & 18.69 \\
\hline
\end{tabular}




\begin{tabular}{lrrrrr}
\hline \multicolumn{6}{c}{ The Frequency of incentive provision } \\
\hline & max sum & outreach & reimb. rate & poorest & women \\
\hline share of LOs & 0.25 & 0.35 & 0.29 & 0.19 & 0.26 \\
\hline
\end{tabular}

\section{D.2 Monitoring}

\section{What is done during monitoring}

\begin{tabular}{lrr}
\hline & share of answers 5,6 & $N$ \\
\hline Asking the borrower about plans for the future & 0.68 & 775 \\
Giving advice on budgeting & 0.693 & 773 \\
Giving advice on running the enterprise & 0.798 & 768 \\
Checking account records & 0.505 & 772 \\
Checking the physical state of enterprise & 0.777 & 767 \\
\hline
\end{tabular}

$1=$ never $, \ldots, 6=$ very often

\begin{tabular}{lrr}
\hline \multicolumn{3}{c}{ What makes monitoring difficult } \\
\hline & share of answers 5,6 & $N$ \\
\hline Distance to Borrower & 0.541 & 777 \\
Time necessary for monitoring & 0.533 & 775 \\
Non-cooperativeness of borrower & 0.415 & 768 \\
\hline
\end{tabular}

scale: $1=$ not important at all, $6=$ very important 


\section{D.3 Discretion}

\begin{tabular}{|c|c|c|}
\hline \multicolumn{3}{|l|}{ Discretion when reporting is required } \\
\hline & $N$ & Percentage \\
\hline You always report immediately & 192 & 25 \\
\hline $\begin{array}{l}\text { You usually report immediately, but sometimes you give } \\
\text { a borrower some additional time before reporting }\end{array}$ & 393 & 51 \\
\hline $\begin{array}{l}\text { You usually report immediately, but sometimes you do } \\
\text { not, on your discretion, for example if you think that it } \\
\text { will be better for the borrower. }\end{array}$ & 146 & 19 \\
\hline $\begin{array}{l}\text { You often take decisions on your own even when the } \\
\text { guidelines prescribe to do something else }\end{array}$ & 47 & 6 \\
\hline Total & 778 & 100 \\
\hline \multicolumn{3}{|c|}{ Discretion when imposing sanctions is required } \\
\hline & $N$ & Percentage \\
\hline You always report immediately and sanction is imposed & 259 & 33 \\
\hline $\begin{array}{l}\text { You usually report immediately but you sometimes give } \\
\text { some additional time before }\end{array}$ & 328 & 42 \\
\hline $\begin{array}{l}\text { You usually report immediately, but sometimes you do } \\
\text { not, on your discretion, but do something discretion in } \\
\text { favour of the borrower }\end{array}$ & 116 & 15 \\
\hline $\begin{array}{l}\text { You often take decisions on your own even when the } \\
\text { guidelines prescribe to do something else }\end{array}$ & 29 & 4 \\
\hline $\begin{array}{l}\text { You always report-but in some cases sanctions are not } \\
\text { imposed immediately due to various reasons }\end{array}$ & 44 & 6 \\
\hline Total & 776 & 100 \\
\hline
\end{tabular}

\section{D.4 Objective Perception}

\begin{tabular}{lrr}
\hline \multicolumn{1}{c}{ Objective Perception } & & \\
\hline & $N$ & Percentage \\
\hline Supporting the poor & 555 & 70 \\
Supporting women & 48 & 6 \\
Making profit & 87 & 11 \\
Financial sustainablity - operate without deficit & 100 & 13 \\
Total & 790 & 100 \\
\hline
\end{tabular}

\begin{tabular}{lrr}
\hline $\begin{array}{l}\text { The alignment of own views on how microloans should be allocated } \\
\text { with MFI's objective }\end{array}$ & $N$ & Percentage \\
\hline & 131 & 16 \\
More or less aligned & 158 & 20 \\
In general, aligned & 272 & 34 \\
Strongly aligned & 238 & 30 \\
Fully aligned & 799 & 100 \\
Total &
\end{tabular}




\begin{tabular}{lrr}
\hline \multicolumn{2}{c}{ To what extent do you agree with practical policies } \\
\hline & $N$ & Percentage \\
\hline More or less agree & 126 & 16 \\
In general, agree & 184 & 23 \\
Strongly agree & 210 & 26 \\
Fully agree & 280 & 35 \\
Total & 800 & 100 \\
\hline
\end{tabular}

\section{E The Impact of Discretion}

\begin{tabular}{|c|c|c|c|c|}
\hline & \multicolumn{2}{|c|}{ Discretion in reporting } & \multicolumn{2}{|c|}{ Discretion in sanctioning } \\
\hline & 1 and 2 & 3 and 4 & 1 and 2 & 3 and 4 \\
\hline \multirow[t]{2}{*}{ age2 } & $.262^{* * *}$ & $.147^{* * *}$ & $.207^{* * *}$ & $.189^{* * *}$ \\
\hline & $(.0758)$ & $(.046)$ & $(.0671)$ & $(.0503)$ \\
\hline \multirow[t]{2}{*}{ age3 } & $.235^{* * *}$ & $.223^{* * *}$ & $.185^{* * *}$ & $.255^{* * *}$ \\
\hline & $(.0778)$ & $(.0472)$ & $(.0683)$ & $(.0516)$ \\
\hline \multirow[t]{2}{*}{ age4 } & $.126^{\sim}$ & $.121^{* *}$ & $.0824^{\sim}$ & $.179 * * *$ \\
\hline & $(.0781)$ & $(.0472)$ & $(.0688)$ & $(.0516)$ \\
\hline \multirow[t]{2}{*}{ age 5} & $-.148^{*}$ & $-.0767^{\sim}$ & -.0766 & $-.0631^{\sim}$ \\
\hline & $(.078)$ & $(.0474)$ & $(.0683)$ & $(.0518)$ \\
\hline \multirow[t]{2}{*}{ gender } & $-.209 * * *$ & $-.251^{* * *}$ & $-.285^{* * *}$ & $-.216^{* * *}$ \\
\hline & $(.0405)$ & $(.0244)$ & $(.0353)$ & $(.0268)$ \\
\hline \multirow[t]{2}{*}{ poverty 2} & -.0499 & .014 & .0238 & -.0358 \\
\hline & $(.0571)$ & $(.034)$ & $(.0497)$ & $(.0372)$ \\
\hline \multirow[t]{2}{*}{ poverty3 } & .0093 & $.0806^{* *}$ & $.0792^{\sim}$ & $.0508^{\sim}$ \\
\hline & $(.0604)$ & $(.0366)$ & $(.0532)$ & $(.0399)$ \\
\hline \multirow[t]{2}{*}{ prob2 } & $.232^{* * *}$ & $.27^{* * *}$ & $.389 * * *$ & $.213^{* * *}$ \\
\hline & $(.0718)$ & $(.0429)$ & $(.0632)$ & $(.0468)$ \\
\hline \multirow[t]{2}{*}{ prob3 } & $.471^{* * *}$ & $.654^{* * *}$ & $.745^{* * *}$ & $.543^{* * *}$ \\
\hline & $(.0674)$ & $(.0406)$ & $(.0598)$ & $(.0442)$ \\
\hline \multirow[t]{2}{*}{ prob4 } & $.611^{* * *}$ & $.744^{* * *}$ & $.837 * * *$ & $.668^{* * *}$ \\
\hline & $(.0678)$ & $(.0414)$ & $(.0599)$ & $(.0453)$ \\
\hline \multirow[t]{2}{*}{ loan_size2 } & -.0538 & -.0166 & $-.0616^{\sim}$ & -.0037 \\
\hline & $(.0575)$ & $(.0344)$ & $(.0501)$ & $(.0376)$ \\
\hline \multirow[t]{2}{*}{ loan_size3 } & $-.259 * * *$ & $-.224^{* * *}$ & $-.21^{* * *}$ & $-.22^{* * *}$ \\
\hline & $(.0547)$ & $(.0329)$ & $(.0484)$ & $(.0357)$ \\
\hline \multirow[t]{2}{*}{ monit2 } & -.0149 & $-.0817^{* *}$ & .0174 & $-.115^{* * *}$ \\
\hline & $(.056)$ & $(.0337)$ & $(.049)$ & $(.0368)$ \\
\hline \multirow[t]{2}{*}{ monit3 } & $-.509 * * *$ & $-.537^{* * *}$ & $-.544^{* * *}$ & $-.527 * * *$ \\
\hline & $(.0545)$ & $(.0328)$ & $(.0479)$ & $(.0359)$ \\
\hline \multirow[t]{2}{*}{ savings2 } & $.229 * * *$ & $.273^{* * *}$ & $.239 * * *$ & $.288^{* * *}$ \\
\hline & $(.0549)$ & $(.033)$ & $(.0478)$ & $(.0363)$ \\
\hline \multirow[t]{2}{*}{ savings3 } & $.284^{* * *}$ & $.34 * * *$ & $.212^{* * *}$ & $.358 * * *$ \\
\hline & $(.0562)$ & $(.0341)$ & $(.0495)$ & $(.0372)$ \\
\hline \multirow[t]{2}{*}{ cons } & -.0427 & -.0212 & $-.0908 * *$ & -.0049 \\
\hline & $(.0515)$ & $(.0307)$ & $(.0447)$ & $(.0337)$ \\
\hline
\end{tabular}




\section{References}

Aghion, Philippe and Jean Tirole, "Formal and real authority in organizations," Journal of Political Economy, 1997, pp. 1-29.

Agier, Isabelle and Ariane Szafarz, "Subjectivity in credit allocation to micro-entrepreneurs: evidence from Brazil," Small Business Economics, 2012, pp. $1-13$.

Armendáriz, Beatriz and Jonathan Morduch, The economics of microfinance, The MIT Press, 2010.

Battilana, Julie and Silvia Dorado, "Building sustainable hybrid organizations: The case of commercial microfinance organizations," Academy of Management Journal, 2010, 53 (6), 1419-1440.

Berger, Allen N., Nathan H. Miller, Mitchell A. Petersen, Raghuram G. Rajan, and Jeremy C. Stein, "Does function follow organizational form? Evidence from the lending practices of large and small banks," Journal of Financial Economics, 2005, 76 (2), 237-269.

Canales, Rodrigo, "Rule bending, sociological citizenship, and organizational contestation in microfinance," Regulation and Governance, 2011, 5 (1), 90 117 .

Cole, Shawn and Esther Duflo, "Banking Reform in India," in "India Policy Forum," Vol. 1 Global Economy and Development Program, The Brookings Institution 2004, pp. 277-332.

Cull, Robert, Asli Demirgüç-Kunt, and Jonathan Morduch, "Microfinance meets the market," Journal of Economic Perspectives, 2009, 23 (1), $167-192$.

Harrison, Glenn W. and John A. List, "Field experiments," Journal of Economic Literature, 2004, 42 (4), 1009-1055.

Hertzberg, Andrew, Jose Liberti, and Daniel Paravisini, "Information and incentives inside the firm: Evidence from loan officer rotation," The Journal of Finance, 2010, 65 (3), 795-828.

Labie, Marc, Pierre-Guillaume Méon, Roy Mersland, and Ariane Szafarz, "Discrimination by Microcredit Officers: Theory and Evidence on Disability in Uganda," CEB Working Paper 10/00\%, 2010.

Levitt, Steven D. and John A. List, "Field experiments in economics: The past, the present, and the future," European Economic Review, 2009, 53 (1), $1-18$.

McFadden, Daniel, Conditional logit analysis of qualitative choice behavior, Academic Press:NewYork,

Sagamba, Moïse, Oleg Shchetinin, and Nurmukhammad Yusupov, "Do Microloan Officers Want to Lend to the Less Advantaged? Evidence from a Choice Experiment," World Development, 2013, 42, 182-198.

The World Bank, "Enterprise Surveys (http://www.enterprisesurveys.org)," 2011. 